\title{
Regional variation in incidence and case fatality of myocardial infarction among young women in England, Scotland and Wales
}

\author{
N R Dunn, A Arscott, M Thorogood, B Faragher, L de Caestecker, T M MacDonald, \\ C McCollum, S Thomas, R D Mann
}

Drug Safety Research Unit, Bursledon Hall, Southampton SO31 1AA

N R Dunn A Arscott

R D Mann

London School of Hygiene and Tropical Medicine, London M Thorogood

Department of Organisational Health Psychology,

Manchester School of Management, UMIST, Manchester B Faragher

Department of Public Health, Greater Glasgow Health Board, Glasgow

L de Caestecker

Medicines Monitoring Unit, Department of Clinical Pharmacology and Therapeutics, Ninewells Hospital Medical School, Dundee

T M MacDonald

Department of Surgery, South

Manchester University Hospital, West

Didsbury, Manchester

C McCollum

Wolfson Unit of Clinical Pharmacology, University of

Newcastle,

Newcastle upon Tyne

$S$ Thomas

Correspondence to: Dr Dunn

Accepted for publication 1 October 1999

\begin{abstract}
Objectives-To examine the regional variation in incidence and case fatality of myocardial infarction among young women.

Design-Cross sectional survey, using population based incidence data.

Setting-England, Scotland and Wales.

Subjects-Subjects were women aged 16-44 with a diagnosis of myocardial infarction between 1 October 1993 and 15 October 1995.

Outcome measures-Incidence of myocardial infarction per 100000 women years, with case fatality as a percentage of total cases.

Results-Incidence of myocardial infarction rose steeply from age 33 upwards, (maximum $=20.2$ cases per 100000 women years at age 44). The adjusted incidence rate for myocardial infarction was $3.7(95 \%$ CI 3.2, 4.2) times greater in Scotland than in southern England. In contrast, case fatality was significantly lower in Scotland: $18.5 \%$ (95\% CI $13.1 \%$, $25.0 \%)$, compared with $31.0 \%$ (95\% CI $25.9 \%, 36.0 \%$ ) in southern England.

Conclusions-The incidence of myocardial infarction varied widely within the United Kingdom. Case fatality variation may reflect differences in ambulance response, or in diagnostic acumen, within the regions.
\end{abstract}

(F Epidemiol Community Health 2000;54:293-298)

Although ischaemic heart disease is the leading cause of death among women in the United Kingdom, most research is carried out among men, and the findings may not be applicable to women. It has been known for over a 100 years that there are marked regional variations in mortality from the disease in the United Kingdom $^{1}$ and these variations persist. ${ }^{2}$ The British Regional Heart Study has examined the potential causes for this variation among men, ${ }^{3}$ but there have been no reports from studies of women. We report the incidence of myocardial infarction among women of childbearing age in different regions of England, Scotland and Wales, standardised by age and smoking habit, and the incidence of myocardial infarction in one year age bands, using data from a large population based case-control study. We also report the regional case fatality.
Methods

This was a cross sectional survey using data for the MICA study, which was a community based case-control study within England, Scotland and Wales, examining the association between myocardial infarction and use of oral contraception. ${ }^{4}$ Its main results have been published elsewhere. ${ }^{5}$ Cases were women, who had a myocardial infarction between 1 October 1993 and 16 October 1995, drawn from the total female population aged $16-44$. They were identified from hospital inpatient statistics, or death certificates from the Office for National Statistics (England and Wales) or the Registrar General's Office (Scotland), using International Classification of Diseases diagnostic codes of 410 (version 9) or I21 (version 10). A validation study in Tayside, Scotland, showed $67 \%$ sensitivity and $100 \%$ specificity in using these codes only for identifying the cases. ${ }^{6}$ Each case diagnosis was validated by three cardiologists, blinded to exposure status, based on WHO criteria. ${ }^{7}$ Data on exposure and risk factors were obtained primarily by interview with the subject (or her proxy, when deceased).

There were 1224 potential cases identified from the data sources. We excluded 46 of these because of incorrect International Classification of Diseases diagnostic code, and a further 63 that were classified as invalid by the diagnostic committee. From the remaining cases we have used two methods to calculate the numerator for the incidence rates, as detailed in figure 1.

INTERVIEWED MYOCARDIAL INFARCTION

All the cases that were interviewed in the MICA study, $n=448$. These constitute $60.3 \%$ of those cases of myocardial infarction, confirmed by the diagnostic committee.

TOTAL MYOCARDIAL INFARCTION

These included all cases confirmed as valid by the diagnostic committee $(n=743)$. There were also 145 cases for which no, or inadequate, hospital records from their admission could be found. These cases were not submitted to the diagnostic committee. We have assumed that $92.2 \%$ of these would have been confirmed as a valid diagnosis by the committee, if their records had been available, (as this was the proportion confirmed of the cases submitted), and included them in the numerator. There were also 227 cases that were excluded because of medical exclusion criteria in their hospital notes (for example, hysterectomy), and thus 
were not submitted to the diagnostic committee. We have included $92.2 \%$ of these, as well.

The denominator was the total female population aged 16-44 for each area or region. We created four regions to make comparisons between rates; these were according to the scheme used by the British Regional Heart Study. ${ }^{3}$ The rates were directly standardised using the appropriate England and Wales female population. Regional and national prevalence of smoking was obtained from the General Household Survey. ${ }^{8}$
Fatal cases were defined as those dying within 28 days of the date of occurrence of myocardial infarction. Case fatality was defined as the percentage of total number deceased/ total number of myocardial infarction cases.

\section{Results}

Figure 2 shows the incidence rate of "total" myocardial infarction cases per 100000 woman years, by one year age bands. The rate increased steeply from a level of 3.0 at age 33, to a maximum of 20.2 cases per 100000 woman years at age 44 . The youngest cases

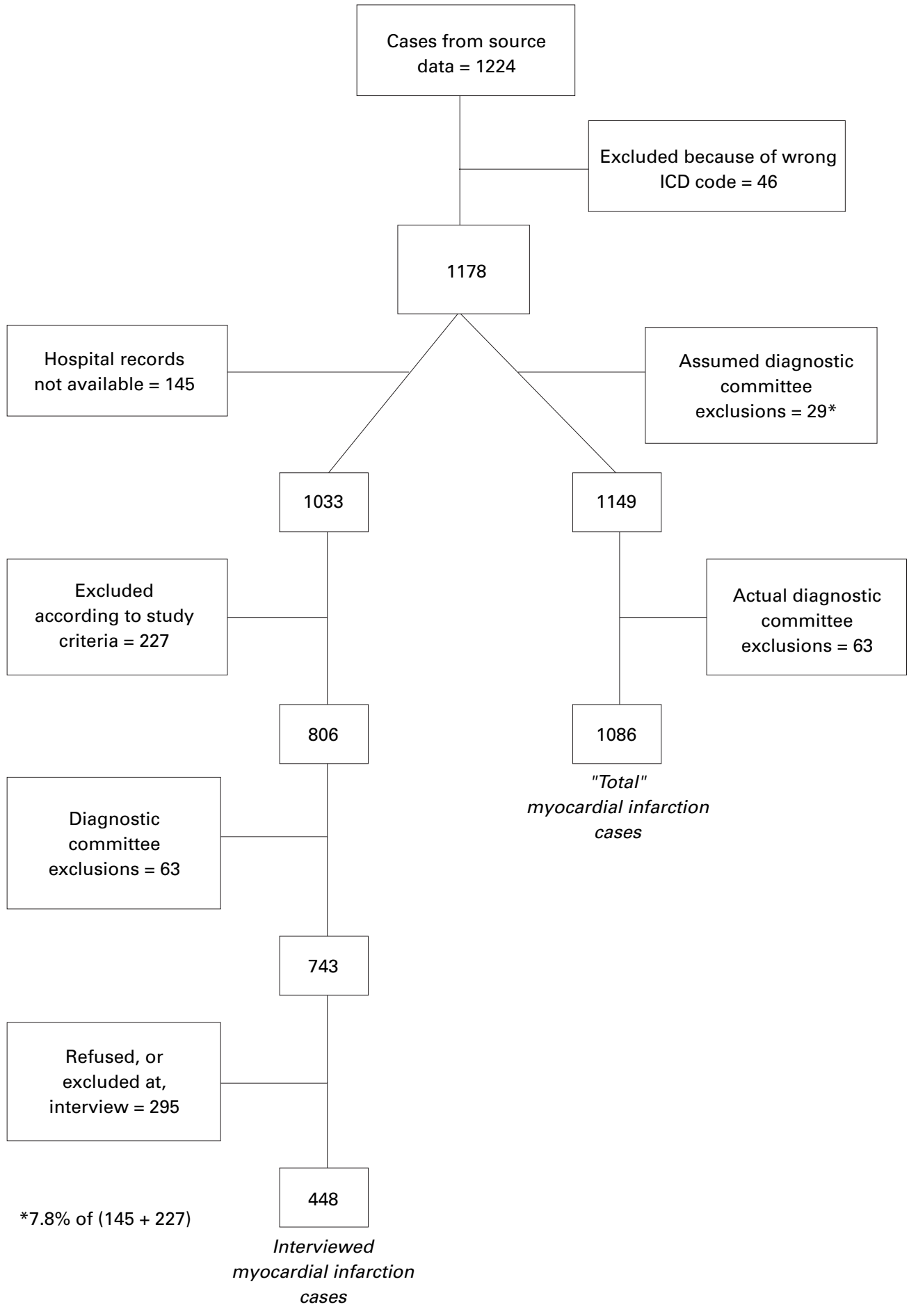

Figure 1 Flow chart to show accrual of interviewed and "total" cases". 


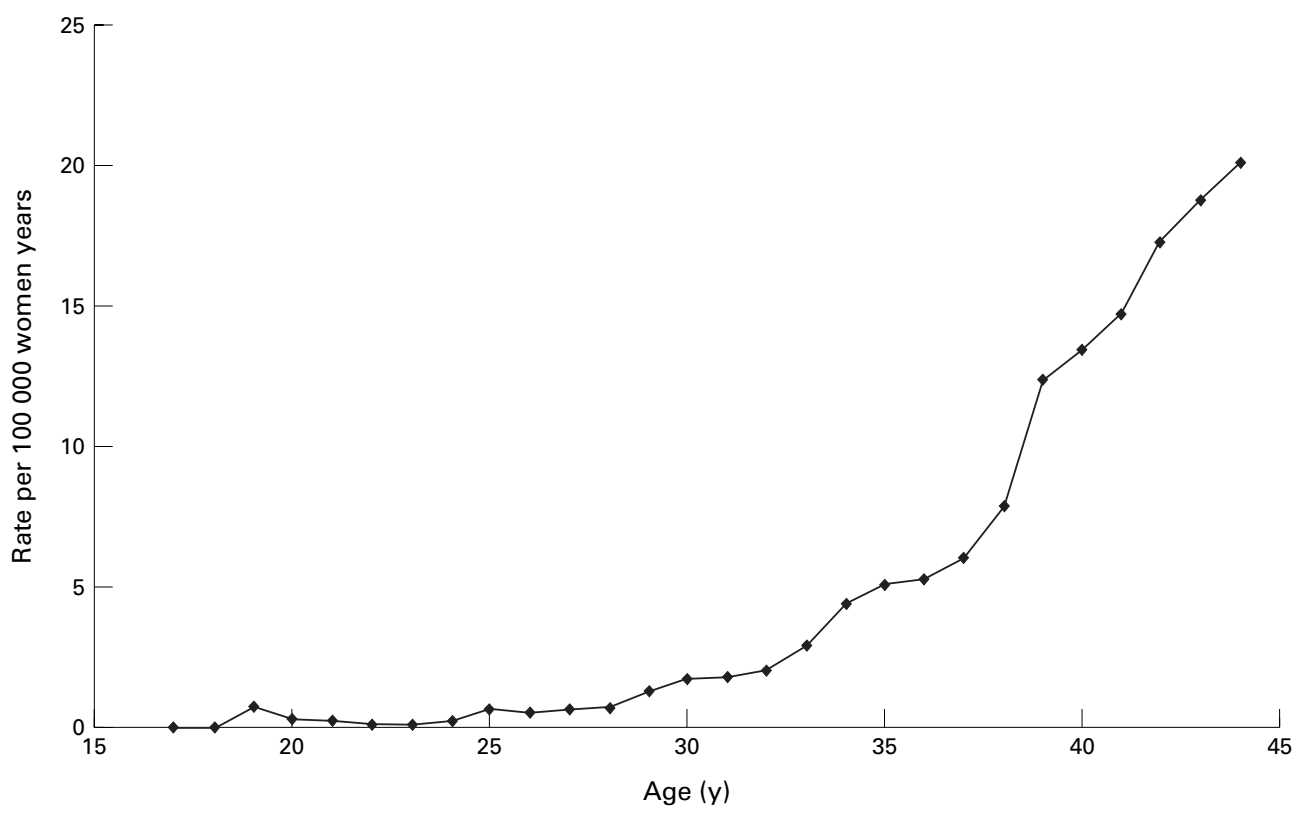

Figure 2 Rate of "total" myocardial infarction, by age.

were aged 19, of which there were three. The age standardised rate of "total" cases with myocardial infarction in the age group 16-44 was 4.8 per 100000 woman years.

Figure 3 is a map showing the distribution of the unadjusted rates for "total" myocardial infarction in postal areas. It shows clearly that the highest rates were in Scotland and north Wales, with relatively high rates in a belt stretching east-west from Liverpool to Hull, south Wales and south west England. The lowest rates were in the south east of England. The range of values was from 0 to 33, (mean 7.01 , SD 4.59), cases per 100000 woman years, with most of the highest rates in Scottish areas.

Table 1 shows the rates in the four regions, both unadjusted and standardised by age and smoking habit, using those myocardial infarction cases who were interviewed (and thus smoking history was known) as the numerator $(n=448)$. It shows increasing risk from south to north, both in the unadjusted and adjusted rate ratios: Scottish women had a risk of myocardial infarction 3.7 times that of their southern English counterparts, even when adjusting for differences in age distribution and prevalence of smoking. Some of the difference between Scotland and England in this analysis may have been accounted for by a difference in interview rates (in Scotland $77.5 \%$ of confirmed cases, and in the south of England, for example, $56.9 \%)$. When the expected number of cases in the south of England was increased to allow for this, the adjusted rate ratio for Scotland became 3.07 (95\% CI 2.69, 3.5).

The overall, unadjusted, mortality rate in women aged 16-44 for England and Wales was 1.17 per 100000 woman years, and for Scotland, 1.51 per 100000 woman years. Case fatality for the different regions and selected urban areas are shown in table 2 . There was a gradient of risk of fatality that was the inverse of the incidence rate of myocardial infarction: in the south of England, the proportion was
$31 \%(95 \%$ CI 25.9, 36.0), whereas in Scotland, it was $18.1 \%$ (95\% CI 12.7, 24.6). The decreasing trend from south to north was statistically significant $\left(\chi^{2}\right.$ for trend $=9.81$, $\mathrm{p}=0.002)$. There was wide variation between the urban areas, the proportion in London being twice that in Liverpool, although the difference was not statistically significant $\left(\chi^{2}=3.63, \mathrm{p}=0.06\right)$.

This same trend of case fatality was observed: (a) if we made the assumption that all the potential cases with no hospital notes $(n=145)$ were not true myocardial infarction cases, and (b) if we only included those cases that were confirmed as valid by the diagnostic committee ( $n=743$, see fig 1$)$. Data from these analyses are not shown.

\section{Discussion}

The most important findings from this study are firstly that the unadjusted regional variation in incidence of myocardial infarction, as reflected by a rate ratio between Scotland and the south of England of 4.5 (95\% CI 3.4, 5.8), persisted even after adjustment for smoking and age (adjusted rate ratio 3.7, 95\% CI 3.2, 4.2). Age was a very important factor in the aetiology of myocardial infarction, as shown in figure 2, and the population attributable fraction of smoking as a risk factor for myocardial infarction in this age group of women was $73 \% .^{5}$ It is unlikely that the other known cardiovascular risk factors can fully account for this marked regional variation: other unknown factor(s) (environmental or genetic) probably play a part.

Secondly, there was a surprising difference in the fatality rate between Scotland $(18.6 \%)$ and southern England (31\%), which was the reverse of that expected from the incidence rates of myocardial infarction. This could have been because of under ascertainment of the number of deaths from myocardial infarction in Scotland, relative to England. WHO 


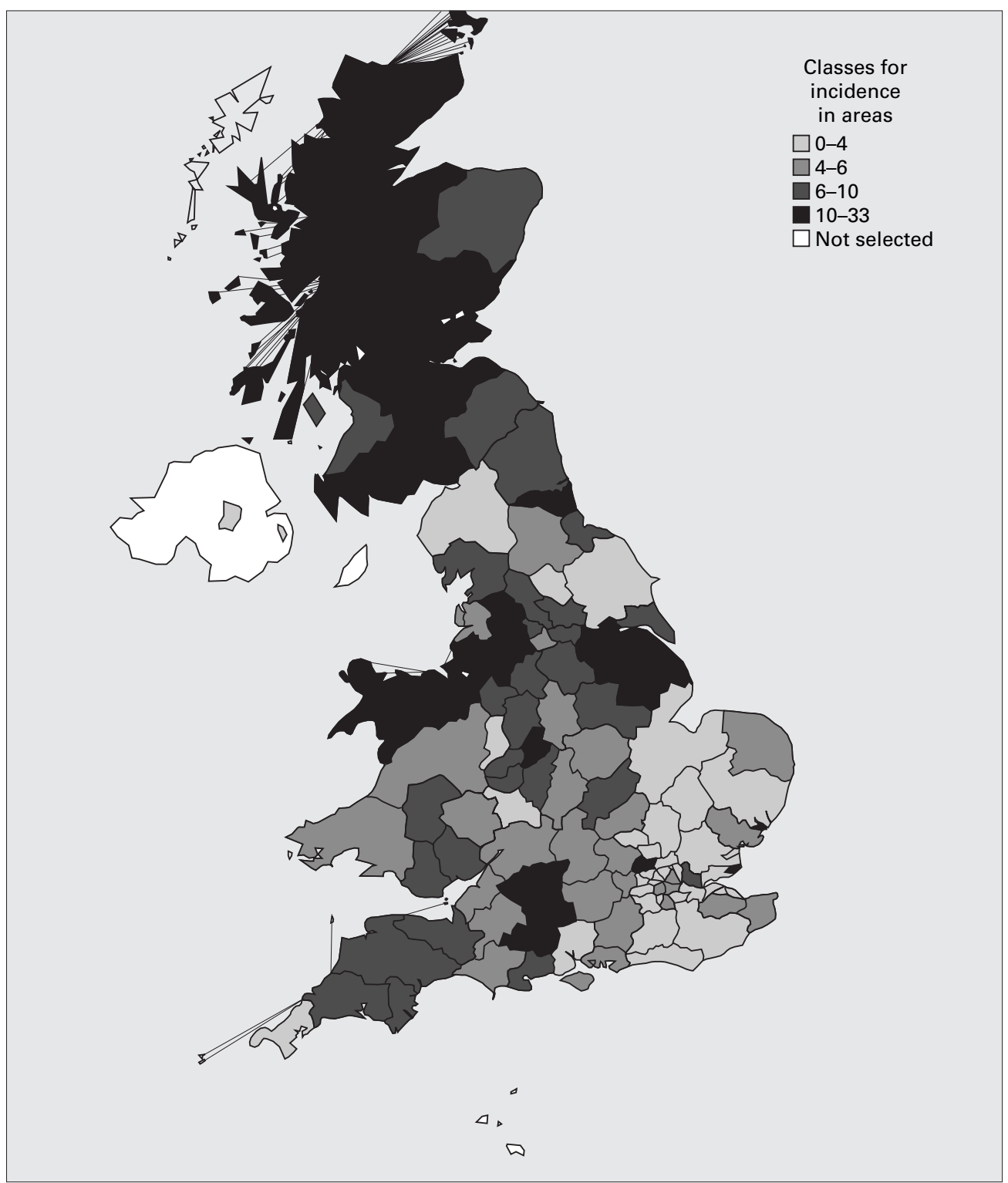

Figure 3 Myocardial infarction per 100000 women age 25-44 in quartiles.

MONICA data on myocardial infarction in north Glasgow between 1985 and 1991 showed a case fatality of $36 \%$ among 35-44 year old women. ${ }^{9}$ However, north Glasgow is not typical of Scotland, as it is an area of socioeconomic deprivation. ${ }^{10}$ Furthermore, the period of data collection was five to 10 years earlier than MICA. There could also have been under ascertainment of the number of surviving myocardial infarction cases in England, relative to Scotland. It seems unlikely that such a systematic bias should exist in these government data, and the fatality rates for this study in
England were compatible with case fatality of $33 \%$ for women aged $<45$ years quoted in another study from three health districts in England and Wales. ${ }^{11}$ However, this does not exclude the possibility that there is under diagnosis of myocardial infarction in young women in England and Wales, compared with Scotland.

Assuming that the data were not biased, it is possible that the difference in case fatality is attributable to random error. The total number of fatal cases in Scotland was 33 over two years. However, the Register General's Office

Table 1 Regional variation in incidence rate of myocardial infarction (MI), adjusted for age and smoking

\begin{tabular}{llllll}
\hline & $\begin{array}{l}\text { Number of } \\
\text { interviewed cases } \\
\text { of MI (live and } \\
\text { deceased) }\end{array}$ & Unadjusted rate* & $\begin{array}{l}\text { Unadjusted rate } \\
\text { ratio }(95 \% \text { CI) }\end{array}$ & $\begin{array}{l}\text { Rate } \\
\text { for age andardised } \\
\text { smokingt }\end{array}$ & $\begin{array}{l}\text { Adjusted rate ratio } \\
\text { (95\% CI) }\end{array}$ \\
\hline South England & 116 & 1.27 & 1 & 1.32 & 1 \\
Midlands and Wales & 94 & 2.18 & $1.7(1.3,2.3)$ & 2.37 & $1.8(1.5,2.1)$ \\
North England & 131 & 2.53 & $2.0(1.6,2.6)$ & 2.33 & $1.8(1.5,2.1)$ \\
Scotland & 107 & 5.70 & $4.5(3.4,5.8)$ & 4.83 & $3.7(3.2,4.2)$ \\
\hline
\end{tabular}

*Per 100000 woman years. †Direct standardisation using England and Wales female population aged 20-44. 
Table 2 Case fatality proportion by region

\begin{tabular}{lccl}
\hline Region & $\begin{array}{l}\text { Number of } \\
\text { deceased cases }\end{array}$ & $\begin{array}{l}\text { Number of } \\
\text { live cases }\end{array}$ & $\begin{array}{l}\text { Case fatality \% } \\
\text { (95\% CI) }\end{array}$ \\
\hline South England & 100 & 223 & $31.0(25.9,36.0)$ \\
$\quad$ Inner London & 23 & 39 & $37.1(25.2,50.3)$ \\
Midlands and Wales & 57 & 166 & $25.6(19.8,31.3)$ \\
North England & 87 & 275 & $24.0(19.6,28.4)$ \\
$\quad$ Manchester & 8 & 22 & $26.7(12.3,45.9)$ \\
$\quad$ Liverpool & 7 & 30 & $18.9(8.0,35.2)$ \\
Scotland & 33 & 145 & $18.5(13.1,25.0)$ \\
\hline
\end{tabular}

mortality data shows the mean (SD) annual number of deaths for women aged 15-44 for the years 1993-1996 inclusive to have been 17.75 (3.83), giving a mean case fatality of $20.1 \%$ (95\% CI 14.7, 27.0). Although the confidence intervals for this fatality rate overlap those for the south of England, there is still a large difference in the point estimate.

If there is a true difference between the case fatality in Scotland and the south of England, the causes are most likely to relate predominantly to ambulance and patient response times from the onset of symptoms. Norris and colleagues showed that $91 \%$ of fatalities in patients under 55 occur outside hospital. ${ }^{11}$ Another study from Nottingham confirms that most deaths from myocardial infarction occur outside hospital. ${ }^{12}$

A "chain of survival", proposed by the American Heart Association, has shown that the length of time between onset of symptoms or collapse, and the arrival of a trained ambulance crew is vital. ${ }^{13}$ Ambulance delays of longer than eight minutes to victims of cardiac arrest leads to a high probability of an unfavourable outcome. ${ }^{14}$ Prompt attempts at cardiopulmonary resuscitation and defibrillation are particularly important in younger people, who are more likely to respond to resuscitation attempts. ${ }^{14}$ There is evidence of considerable variation in ambulance response times between England, Scotland and Wales during the period of case incidence of the MICA study. The average proportion of cardiac arrest calls in England with response time of eight minutes or less was $56 \%$ in 1994 1995 , but the range was from $13 \%$ (London) to $75 \%$ (Mersey). In Scotland, as a whole, the equivalent figure was $61 \%$ for the period 1991-1995. In Scotland, the Heartstart Programme had resulted in all emergency ambulances being equipped with defibrillators and a trained crew by mid-1990..$^{15}$ This programme was completed before similar initiatives in England and Wales. It is thus possible that the lower case fatality proportion in Scotland reflects better response times and actions by ambulance crews, relative to their colleagues in the south of England. The especially poor ambulance response rates in London appear unique and may contribute to the high case fatality in this city. When the London cases were excluded from those in the south of England, the case fatality (30.5\%), was still significantly higher than that of Scotland $(18.1 \%$, $\chi^{2}=7.36, p=0.007$ ). A study by Leslie and colleagues has suggested that the impact of the Heartstart Scotland programme on coronary mortality in north Glasgow was minimal. ${ }^{15}$ In
KEY POINTS

- Scotland has an incidence rate of myocardial infarction in young women approximately four times higher than the south of England.

- Adjustment for age and smoking did not abolish this regional variation.

- The case fatality rate is higher in the south of England than in Scotland (31\% versus $18.5 \%)$.

- Regional variation in case fatality is most likely to reflect variation in factors operating before the patient arrives in hospital.

contrast, another study in Scotland suggested that the Heartstart programme has had a considerable impact on survival of patients after collapse in the community with ventricular fibrillation. ${ }^{16}$

Another contributory factor to the regional difference in case fatality could be variability in efficiency of treatment for myocardial infarction within hospitals, for example, use of low dose aspirin, $\beta$ blockers or thrombolytic therapy. This does not seem very plausible, but merits further investigation.

The lower case fatality in Scotland is in keeping with WHO MONICA project results that have shown that case fatality for women, aged 35-64, was significantly lower in countries with a higher event rate for myocardial infarction, for example, in Finland (Kuopio). ${ }^{17}$

These data from the MICA study have shown that the regional variations of myocardial infarction incidence in Scotland and England for men applied to young women as well. These differences persisted after adjustment for age and smoking. The case fatality in Scotland was significantly lower than in the south of England, which may be explained, by different diagnostic rates, or by better ambulance response. This finding merits further research, and exploration of other factors such as the extent of use of cardiopulmonary resuscitation by witnesses, delay between onset of symptoms and the call to an ambulance, and the consistency of therapeutic interventions in hospital.

Nicholas Dunn and Ronald Mann (principal investigator) initiated the study and wrote the protocol with Margaret Thorogood, Linda de Caestecker, Charles McCollum, Thomas M MacDonald and Simon Thomas. Margaret Thorogood was principal scientific advisor. Brian Faragher carried out the statistical analysis. Ann Arscott was project manager and in charge of data handling. All the authors contributed to the revision of the paper, which was originally drafted by Nicholas Dunn. All the authors sat on the Steering Committee throughout the study.

Funding: unconditional grant from NV Organon and Schering AG. Conflicts of interest: none.

1 Shaper AG, Elford J. Regional variations in coronary heart disease in Great Britain: risk factors and changes in environment. In: Marnot $\mathrm{M}$, Enlot $\mathrm{P}$, eds. Coronary heart OUP, 1992.

2 Elford J, Phillips AN, Thomson AG, et al. Migration and geographic variations in ischaemic heart disease in Great Britain. Lancet 1989;i;343-6.

3 Shaper AG, Pocock SJ, Walker M, et al. British Regional Heart Study: cardiovascular risk factors in middle-aged men in 24 towns. BMJ 1981;283:179-86. 
4 Dunn NR, Thorogood M, de Caestecker L, et al. Myocardial infarction and oral contraceptives, a retrospective casecontrol study in England and Scotland ('MICA'
Pharmacoepidemiology and Drug Safety 1997;6:283-9.

5 Dunn NR, Thorogood M, Faragher B, et al. Oral contraceptives and myocardial infarction: results of the MICA casecontrol study. BMJ 1999;318:1579-84.

6 McAlpine R, Pringle S, Pringle T, et al. A study to determine the sensitivity and specificity of hospital discharge diagnosis data used in the MICA study. Pharmacoepidemiology and Drug Safety 1998;7:311-18.

7 WHO Collaborative Study of Cardiovascular Disease and Steroid Hormone Contraception. A multinational casecontrol study of cardiovascular disease and steroid hormone contraceptives. F Clin Epidemiol 1995;48:151347.

8 General Household Survey 1995. London: HMSO, 1995.

9 Morrison C, Woodward M, Leslie W, et al. Effect of socio-economic group on incidence of management and socio-economic group on incidence of management and nity coronary event register. BMF 1997;314:541-6.

10 Watt GCM, Ecob R. Mortality in Glasgow and Edinburgh: a paradigm of inequality in health. $\mathcal{F}$ Epidermiol Community Health 1992;46:498-505.

11 Norris RM on behalf of UK Heart Attack Study Collaborating Group: Fatality outside hospital from acute coronary events in three British Health districts. BMf 1998;316:1065-70.
12 Brown N, Young T, Gray D, et al. Inpatient deathsfrom acute myocardial infarction, 1982-92: analysis of data in acute myocardial infarction, 1982-92: analysis of data in
the Nottingham heart attack register. BMF 1997;315:15964 .

13 Cummiaz RO, Ornato JP, Thies WH, et al. Improving survival from sudden cardiac arrest: the 'chain of survival' concept. A statement for health professionals from the Advanced Life Support sub committee and the Emergency Cardiac Care Committee, American Heart Association Circulation 1991;83:1832-47.

14 NHS Executive. Review of Ambulance Performance Standards. Final report of Steering Group. London: NHS Executive, Final 1996.

15 Leslie WS, Fitzpatrick B, Morrison CE, et al. Out of hospidisease: a comp son of survival before and after the introduction of defibrillators in ambulances. Heart 1996;75:195-9.

16 Sedgwick ML, Dalziel K, Watson J, et al. Performance of an established system of first responder out-of-hospital defibrillation. The results of the second year of the Heartstart Scotland project in the 'Ustein style'. Resuscitation 1993;26:75-88.

17 Tunstall-Pedoe H, Kuulasmaa K, Amouyel P, et al. Myocardial infarction and coronary deaths in the WHO MONICA project. Registration procedures, event rates and case fatality rates in 38 populations from 21 countries in 4 continents. Circulation 1994;90:583-612. 